Magdalena Grothe ${ }^{1}$

BARTOSZ ŻUKOWSKI

\title{
SHORT- AND LONG-TERM SOCIAL INTERACTIONS FROM THE GAME THEORETICAL PERSPECTIVE: A COGNITIVE APPROACH
}

\section{Introduction}

Game theory is a growing field of analytical modelling of interactions between agents. It has found many applications in economics and business administration, as well as in social and cognitive sciences. Among various forms of one-off and multi-period games, the probably most popular one is known as a prisoner's dilemma. This paper analyses the social interactions from the perspective of the equilibria resulting from the prisoner's dilemma models with a short and indefinite time horizon.

A one-period interaction modelled in the prisoner's dilemma setting results in an equilibrium point where the agents are maximising their short-term profit and thus, interacting, they reach a suboptimal point of overall welfare. However, in a model with an indefinite time framework, it is likely to reach an equilibrium which is consistent with the cooperative behaviour over a longer period of time. In result, an optimal point from the perspective of welfare is reached. In the following analysis, we relate these model results to social interactions and discuss their possible applications in cognitive science.

The paper is related to the literature on game theory and its applications in social interactions. Research in game theory dates back to the nineteenth century, when, among others, the theories of strategic interaction in oligopolies have been

1 Views expressed in this paper do not necessarily represent the views of the European Central Bank. 
developed (see, e.g. Bertrand, 1883, or Varian, 2006 for an overview). In the first half of the 20th century, Neumann and Morgenstern (1944) applied game theory to the economic interactions among agents who maximise their utility (see also Neumann, 1928 or Copeland, 1945 for the review of Neumann, Morgenstern, 1944). Following this, the field grew intensively, with the range of underlying concepts developed and extensive applications to many areas of economic research (see, e.g. Shapiro, 1989; Kreps, 1990 and Selten, 1999). In particular, in 1994 John C. Harsanyi, John F. Nash Jr. and Reinhard Selten received the Nobel Prize in Economic Sciences "for their pioneering analysis of equilibria in the theory of non-cooperative games". Following this work, game theoretical results have been validated from the behavioural perspective, as well as by experiments (see, e.g. Smith, 1992 or Crawford, 1997), ${ }^{2}$ while the framework to analyse conflict and cooperation of economic agents has been developed further. ${ }^{3}$ In cognitive science, game theory has been also widely used for a variety of applications and research questions (see, e.g. Carlsson, 1998; Skyrms, 2010). The contribution of this paper is to add some new aspects to this discussion.

The remainder of the paper is structured as follows. Section 2 outlines a basic model of the prisoner's dilemma, with focus on a one-period and multi-period interactions. Section 3 analyses social interactions from the perspective of the equilibria of prisoner's dilemma game, as derived in section 2 . Section 4 concludes.

\section{Prisoner's dilemma}

The most popular model in the game theory is the prisoner's dilemma. The game stems originally from the research conducted for military purposes in the middle of the 20th century. The following section discusses, first, the one-period interaction, outlining the game's set-up, the Nash equilibrium and the welfare calculation. The second part of the section presents the iterated prisoner's dilemma, discussing possible strategies and their dominance.

2002 Nobel Prize in Economic Sciences for Daniel Kahneman "for having integrated insights from psychological research into economic science, especially concerning human judgment and decision-making under uncertainty" and for Vernon L. Smith "for having established laboratory experiments as a tool in empirical economic analysis, especially in the study of alternative market mechanisms".

32005 Nobel Prize in Economic Sciences for Robert J. Aumann and Thomas C. Schelling "for having enhanced our understanding of conflict and cooperation through game-theory analysis". 


\subsection{One-period interaction}

Prisoner's dilemma game is a standard example of a cooperation problem. The game in its simple set-up has two parties, who interact in a one-off meeting. Originally, the game formulated by M. Flood and M. Dresher in the context of military-related research was formalised in Kuhn and Tucker (1950). The game is described as a problem of two prisoners, accused of committing jointly a crime, and facing an interrogation. Each of them can decide, without consulting with the other one, to admit the crime or not. If they both refuse to confess, they will both get only a mild conviction - an outcome resulting in a maximal joint welfare. In case one of the prisoners confesses, while the other will deny the crime, the latter will suffer a long conviction, while the confessing prisoner will be set free - an outcome implying a maximum profit for one of the parties and a maximal loss for another party.

In a more general setting, each of the players faces a simple choice: to "cooperate" or "defect". The outcomes of the game for each of the players can be summarised as follows:

\begin{tabular}{|c|c|c|c|}
\hline & & & \\
\hline & & cooperate & defect \\
\hline & cooperate & $(\mathrm{A}, \mathrm{A})$ & $(\mathrm{B}, \mathrm{C})$ \\
\hline & defect & $(\mathrm{C}, \mathrm{B})$ & $(\mathrm{D}, \mathrm{D})$ \\
\hline
\end{tabular}

Fig. 1. Matrix of outcomes for one-period game

where $\mathrm{C}>\mathrm{A}>\mathrm{D}>\mathrm{B}$, and $2 \mathrm{~A}>(\mathrm{B}+\mathrm{C})>2 \mathrm{D}$. In a numerical example, the above setting would correspond to the following:

Player II

\begin{tabular}{cccc|}
\multicolumn{1}{c}{} & \multicolumn{1}{c}{ cooperate } & \multicolumn{1}{c}{ defect } \\
\cline { 3 - 4 } Player I & $\begin{array}{c}\text { cooperate } \\
\text { defect }\end{array}$ & $(100,100)$ & $(0,150)$ \\
\cline { 3 - 4 } & & $(150,0)$ & $(25,25)$ \\
\cline { 3 - 4 } & &
\end{tabular}

Fig. 2. Matrix of payoffs for one-period game 
The outcome always denotes the payoff in units of each of the players, depending on their action as well as the action of the counterparty (i.e. units received by player I, units received by player II). The contingencies involve a choice between "cooperate" and "defect" for each player. This would correspond to "refuse to confess" and "confess" in an original example of the game.

Analysing the possible outcomes from the overall welfare perspective, it is generally optimal that both players "cooperate" with each other, as they would maximise the joint payoff and minimise the inequality of the payoff distribution. However, from the perspective of a strategy, which is an optimal response to the other players' strategies, i.e. from the perspective of Nash equilibrium, the optimal strategy is quite different. Nash equilibrium can be defined as follows. Theorem as in Nash (1950):

Let $(P, R)_{m \times n}$ be the payoffs of a bimatrix game. ${ }^{4}$ Then there exists a mixed strategy $x^{*}=\left(x_{1}{ }^{*}, x_{2}{ }^{*}, \ldots, x_{m}{ }^{*}\right)$ for player I and a mixed strategy $y^{*}=\left(y_{1}{ }^{*}, y_{2}{ }^{*}, \ldots\right.$, $\left.y_{m}{ }^{*}\right)$ for player II such that for any mixed strategy $x=\left(x_{1}, x_{2}, \ldots x_{m}\right)$ for player $\mathrm{I}$ and for any mixed strategy $y=\left(y_{1}, y_{2}, \ldots y_{m}\right)$ for player II,

$$
\left\langle x^{*}, P y^{*}\right\rangle=\sum_{i=1}^{m} \sum_{j=1}^{n} p_{i j} x_{i}^{*} y_{j}^{*} \geq \sum_{i=1}^{m} \sum_{j=1}^{n} p_{i j} x_{i} y_{j}^{*}=\left\langle x, P y^{*}\right\rangle
$$

and

$$
\left\langle x^{*}, R y^{*}\right\rangle=\sum_{i=1}^{m} \sum_{j=1}^{n} r_{i j} x_{i}^{*} y_{j}^{*} \geq \sum_{i=1}^{m} \sum_{j=1}^{n} r_{i j} x_{i}^{*} y_{j}=\left\langle x^{*}, R y\right\rangle
$$

For a broader discussion, see also Raghavan (2002) and Hillas and Kohlberg (2002), as well as Khan and Sun (2002), all in Aumann and Hart (2002).

Nash equilibrium of the prisoner's dilemma game implies the outcome, where both players defect and reach the jointly minimal payoff. The Nash equilibrium is reached by the players following their individual profit maximising strategy, which implies that they would prefer the choice yielding their personal maximum payoff. In particular, the decision faced by each player is that the choice of the strategy "cooperate" is less productive than the choice of the strategy "defect", i.e. C > A in the example above. Knowing this, each player anticipates the strategy of the counterparty, and tries to maximise his profit, given the strat-

${ }^{4}$ A bimatrix game is a finite non-cooperative game with two players I and II, with payoff matrices $P$ and $R$, respectively. 
egy, i.e. $\max ((\mathrm{B}, \mathrm{D}) \mid$ counterparty strategy "defect"). Chammach and Rapoport (1965) show that the analogous result for the Nash equilibrium holds for several available strategies.

Another way to present the same problem is the diagram of choices of one of the players, depending on the unknown decision of another player:

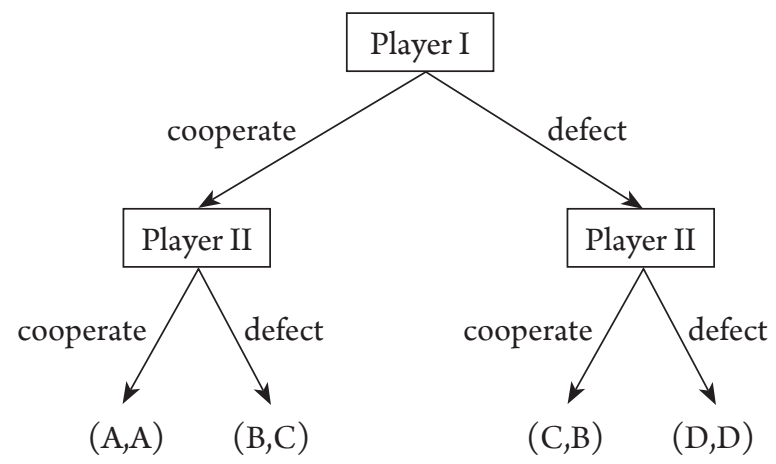

Fig. 3. Diagram of choices for one-period game

In this form, a solution can be found by dividing the game into parts, socalled subgames, with subgame perfect Nash equilibria (see also Harsanyi, Selten, 1988). In the example above, the overall game would consist of two subgames played by player II, with the choice of player I set as exogenous in each of the subgames. The Nash equilibrium derived in this way is also ("defect", "defect").

Overall, the one-period prisoner's dilemma game implies that if players follow a rational expectation of anticipating the counterparty's move, the equilibrium will always be suboptimal form the perspective of (i) individual payoffs and (ii) the overall welfare.

\subsection{Multi-period interactions}

In a repeated prisoner's dilemma game, the uncooperative equilibrium is not straightforward any more. The cooperation can be theoretically supported either in an infinitely repeated game (see, e.g. Rubinstein, 1982), or in a game with a finite number of iterations and an uncertainty about the counterparty's strategy (see, e.g. Kreps et al., 1982). 
As a starting point, consider a two-period game of a prisoner's dilemma with a payoff structure as in section 2.1. The cumulative payoffs of players I and II, depending on possible sequences of choices between "cooperate" and "defect" strategies, are the following:

\begin{tabular}{|c|c|c|}
\hline Iteration 1 & Iteration 2 & Sum payoff \\
\hline \multirow{4}{*}{$(\mathrm{c}, \mathrm{c})$} & $(\mathrm{c}, \mathrm{c})$ & $(200,200)$ \\
\cline { 2 - 3 } & $(\mathrm{c}, \mathrm{d})$ & $(100,250)$ \\
\cline { 2 - 3 } & $(\mathrm{d}, \mathrm{c})$ & $(250,100)$ \\
\cline { 2 - 3 } & $(\mathrm{d}, \mathrm{d})$ & $(125,125)$ \\
\hline \multirow{4}{*}{$(\mathrm{c}, \mathrm{d})$} & $(\mathrm{c}, \mathrm{c})$ & $(100,250)$ \\
\cline { 2 - 3 } & $(\mathrm{c}, \mathrm{d})$ & $(0,300)$ \\
\cline { 2 - 3 } & $(\mathrm{d}, \mathrm{c})$ & $(150,150)$ \\
\cline { 2 - 3 } & $(\mathrm{d}, \mathrm{d})$ & $(25,175)$ \\
\hline \multirow{4}{*}{$(\mathrm{d}, \mathrm{c})$} & $(\mathrm{c}, \mathrm{c})$ & $(250,100)$ \\
\cline { 2 - 3 } & $(\mathrm{c}, \mathrm{d})$ & $(150,150)$ \\
\cline { 2 - 3 } & $(\mathrm{d}, \mathrm{c})$ & $(300,0)$ \\
\cline { 2 - 3 } & $(\mathrm{d}, \mathrm{d})$ & $(175,25)$ \\
\hline \multirow{4}{*}{$(\mathrm{d}, \mathrm{d})$} & $(\mathrm{c}, \mathrm{c})$ & $(125,125)$ \\
\cline { 2 - 3 } & $(\mathrm{c}, \mathrm{d})$ & $(25,175)$ \\
\cline { 2 - 3 } & $(\mathrm{d}, \mathrm{c})$ & $(175,25)$ \\
\cline { 2 - 3 } & $(\mathrm{d}, \mathrm{d})$ & $(50,50)$ \\
\hline
\end{tabular}

Fig. 4. Matrix of payoffs for multi-period game

The solution of this game can be found by identifying subgame perfect Nash equilibria and using backward induction (see, e.g. Harsanyi, Selten, 1988). In the final iteration of the game, each player decides between their two strategies, contingent on the outcome of the previous iterations, i.e. starting in the respective point in the decision tree. The above calculation shows that for any outcome of iteration 1, the strategy "defect" is optimal, in the sense of Nash equilibrium, for each player. As a result, through backward induction, the players would have to decide on their moves for iteration 1, knowing that the outcome of iteration 2 will be ("defect", "defect"). Comparing the payoffs from rows with (d, d) in iteration 2, again, a Nash equilibrium would be ("defect", "defect") in iteration 1.

The same logic can be applied to finitely repeated games. The players anticipate the last round, where it is optimal (in the Nash sense) to defect, and defect in the previous round, going along the decision tree back to the first round. 
However, when the horizon is infinite or the end point is distant and uncertain, other equilibria may occur. One of the possibilities is a strategy, which starts with a cooperative move and always reflects the move of the opponent in the previous round, the so-called "tit-for-tat" strategy. Kreps, Milgrom, Roberts, and Wilson (1982) show that in a prisoner's dilemma game with a small probability of a small fraction of players having a "tit-for-tat" strategy, this strategy starts to dominate and other players converge to it as well. As an outcome, players may as well reach a welfare-optimal equilibrium of cooperation in each round. Confirming this empirically, Axelrod (1984) reports on a contest of an N-step prisonner's dilemma, where participants needed to submit the strategies. In fact, the "tit-fortat" strategy, submitted by A. Rapoport, appeared to be the dominating strategy in the contest (see also, e.g. Chammach, Rapoport 1965, and Rapoport 1970).

To summarise, this section illustrates how the same set-up of interactions can accommodate materially different equilibria, only depending on the horizon of the interactions. In particular, in a game with a one-off interaction, an uncooperative equilibrium is achieved, where agents receive their second-worst pay-offs and overall welfare is suboptimal. A similar result is achieved in a multi-step setting with the end-point of interaction being commonly known and not distant. In contrast, a setting of multi-period interactions with indefinite (or very distant) end-point, may likely result in a cooperative behaviour with higher individual pay-offs and, consequently, a higher overall welfare. All these results are based on rational maximisation of profits from the individual perspective.

In the next section, the theoretic equilibria of one-period and multi-period prisoner's dilemma are related to social interactions.

\section{Social interactions in the equilibrium of prisoner's dilemma - cognitive applications}

The results discussed in section 2 can be used in social sciences in two distinct but complementary ways. First, they can serve as theoretical explanatory model to understand different attitudes of social agents towards cooperative behaviours, depending on whether the horizon of social interaction is finite or not. Second, from the point of view of cognitive science, they provide a successful computational framework to model complex interactions between intelligent agents. 
The explanatory power of the above analysis may seem rather obvious. The correlation between the anticipated horizon of interaction and the increase of cooperative attitudes appears to be fully compatible with everyday experience. In case of both commercial and social interactions, individuals seem to be more likely to cooperate depending on the expected horizon of coexistence. The same is supposed to be true even for international relations. ${ }^{5}$ What is less obvious is how this observation can be used as a persuasive or negotiating tool to obtain optimal point from the perspective of individual payoffs or overall welfare.

The most intriguing aspect of the results presented above is that they can provide a sufficient mathematical explanation for the whole complex of phenomena documented in social psychology. We mean the well-documented fact that the willingness to cooperate increases if agents are faced with potential infinity and inevitability of interaction (see, e.g. Aronson 2011, Darley, Berscheid 1967). For example, it has been observed that xenophobic attitudes decrease as a result of the interaction between people of different ethnic groups, provided that it was seen as unavoidable for the future coexistence (Aronson 2011).

Conventionally, these socio-psychological phenomena have been explained in purely psychological terms. They can, for example, be interpreted within behavioural learning paradigm (as one of many instances of the attitudes shaped by the behaviours), or, alternatively, regarded as an example of cognitive-dissonance reduction (Aronson 2011). Sometimes they are simply considered to be self-explanatory, or at least explainable by common-sense reasons.

While being intuitively appealing, conventional approaches seem insufficient for a precise and formal analysis of social interactions. Also, predictions about likely human behaviours need a more formal underlying model. Consequently, conventional approaches to understanding socio-psychological phenomena are of limited use for the purposes of the operationally-oriented cognitive science. This leads us to the second point mentioned above, i.e. the use of computational framework to model complex interactions between intelligent agents. In contrast to the socio-psychological explanations, the mathematical framework presented in section 2 provides sufficient formal theory for computational modelling of attitude changes in short-term and longer-term social interactions.

5 However, the issue becomes more complex when more sophisticated models are considered. In at least some cases the results considered here can lead to counterintuitive conclusions. Consider, for instance, arms race games or war games with the conventional/nuclear distinction as a determinant of interaction horizon. 
While the theory is very appealing, there still remains a methodological problem of adequacy, i.e., the correspondence of theory to reality. In other words, it seems important to ask whether the theory is true. While this issue is essential if the realistic explanatory theory is needed (i.e., if you want to describe what is really going on in agents' minds), it seems less important form the instrumentalist point of view. In fact, if the proposed formalism is to be applied in the operationally-oriented cognitive science, the issue of adequacy becomes irrelevant. The reason for this is that the model simulating human behavior must not necessarily work the same way as human mind. In the following, we leave it open for discussion, whether the above should be interpreted in a realistic or instrumentalistic manner (even though we are inclined to the latter opinion). This is, in fact, part of a wider problem of the epistemological status of a game-theoretic approach as a whole, which, nevertheless, has been successfully applied from the very beginning of cognitive science.

\section{Conclusion}

In this paper, we discuss the social reactions from a perspective of the game theoretical model of prisoner's dilemma. The model results in largely different equilibria, depending on the length of the interaction between agents. In a shortlived interaction, the model results in a suboptimal point of overall welfare due to the fact that agents maximise their short-term profit and act in an uncooperative manner. In an interaction of long indefinite duration, the model results in an optimal point of overall welfare due to the fact that agents, maximising their long-term overall profit, act in a cooperative manner. Overall, this paper presents theoretically founded explanation of the strategically different behaviour in short-term and long-term social interactions, providing successful computational framework for cognitive modelling.

\section{References}

Aumann, R.J., Hart, S. (eds.) (2002). Handbook of Game Theory with Economic Applications, vol. 3. Amsterdam: Elsevier Science Publishers.

Aumann, R.J., Heifetz, A. (2002). Incomplete information. In: R.J. Aumann, S. Hart (eds.), Handbook of Game Theory with Economic Applications, vol. 3 (pp. 1665-1686). Amsterdam: Elsevier Science Publishers. 
Axelrod, R. (1984). The Evolution of Cooperation. New York: Basic Books.

Aronson, E. (2011). The Social Animal. New York: Worth Publishers.

Bertrand, J.L. F. (1883). Review of Théorie mathematique de la richesse sociale and of Recherches sur les principles mathematiques de la théorie des richesses. Journal des Savants 67: 499-508.

Camerer, C.F. (2003). Behavioral Game Theory: Experiments in Strategic Interaction. Princeton: Princeton University Press.

Capraro, V. (2013). A model of human cooperation in social dilemmas. PLoS ONE 8 (8): $1-6$.

Carlsson, B. (1998). Evolutionary Models in Multi-Agent Systems. Lund University Cognitive Studies 72.

Chammach, A.M., Rapoport, A. (1965). Prisoner's Dilemma: A Study in Conflict and Cooperation. Ann Arbor: University of Michigan Press.

Copeland, A.H. (1945). Review: Theory of games and economic behavior by John von Neumann and Oskar Morgenstern. Bulletin of the American Mathematical Society 51 (7): 498-504.

Crawford, V.P. (1997). Theory and experiment in the analysis of strategic interaction. In: D. Kreps, K. Wallis (eds.), Advances in Economics and Econometrics: Theory and Applications, Seventh World Congress, vol. 1 (pp. 206-242), Cambridge: Cambridge University Press.

Darley, J.M., Berscheid, E. (1967). Increased liking as a result of the anticipation of personal contact. Human Relations 20: 29-40.

Debreu, G. (1970). Economies with a finite set of equilibria. Econometrica 38 (3): 387392.

Fehr, E., Fischbacher, U. (2003). The nature of human altruism. Nature 425 (6960): 785791.

Varian, H.R. (2006). Intermediate microeconomics: A modern approach. New York-London: Norton.

Harsanyi, J.C., Selten R. (1988). A General Theory of Equilibrium Selection in Games. Cambridge, MA: MIT Press.

Hillas, J., Kohlberg, E. (2002). Foundations of strategic equilibrium. In: R.J. Aumann, S. Hart (eds.), Handbook of Game Theory with Economic Applications, vol. 3 (pp. 1597-1663), Amsterdam: Elsevier Science Publishers.

Khan, M.A., Sun, Y. (2002). Non-cooperative games with many players. In: R.J. Aumann, S. Hart (eds.), Handbook of Game Theory with Economic Applications, vol. 3 (pp. 1761-1808), Amsterdam: Elsevier Science Publishers.

Kreps, D.M. (1990). Game Theory and Economic Modelling. Oxford-New York: Oxford University Press.

Kreps, D.M., Wilson, R. (1982). Sequential equilibria. Econometrica 50 (4): 863-894.

Kreps, D.M., Milgrom, P.R., Roberts J., Wilson, R. (1982). Rational cooperation in the finitely repeated prisoners' dilemma. Journal of Economic Theory 27 (2): 245-252.

Kuhn, H.W., Tucker, A.W. (eds.) (1950). Contributions to the Theory of Games, vol. 1. Princeton: Princeton University Press. 
Milgrom, P.R. (1984). Axelrod's "The Evolution of Cooperation". The Rand Journal of Economics 15 (2): 305-309.

Nash, J.F. (1950). Equilibrium points in n-person games. Proceedings of the National Academy of Sciences USA 36: 48-49.

Nash, J.F. (1951). Non-cooperative games. The Annals of Mathematics 54 (2): 286-295.

Neumann, J. von (1928). Zur Theorie der Gesellschaftsspiele. Mathematische Annalen 100 (1): 295-320.

Neumann, J. von, Morgenstern, O. (1944). Theory of Games and Economic Behavior. Princeton, NJ: Princeton University Press.

Raghavan, T.E. S. (2002). Non-zero-sum two-person games. In: R.J. Aumann, S. Hart (eds.), Handbook of Game Theory with Economic Applications, vol. 3 (pp. 16871721), Amsterdam: Elsevier Science Publishers.

Rapoport, A. (1970). N-Person Game Theory. Concepts and Applications. Ann Arbor: University of Michigan Press.

Rubinstein, A. (1982). Perfect equilibrium in a bargaining model. Econometrica 50 (1): 97-110.

Osborne, M.J. (2003). An Introduction to Game Theory. Oxford: Oxford University Press.

Selten, R. (1999). Game Theory and Economic Behavior: Selected Essays, vol. 2. Cheltenham-Northampton: Edward Elgar Publishing.

Shapiro, C. (1989). The theory of business strategy. The Rand Journal of Economics 20 (1): 125-137.

Skyrms, B. (2010). Signals. Evolution, Learning and Information, New York: Oxford University Press.

Smith, V.L. (1992). Game Theory and experimental economics: Beginnings and early influences. History of Political Economy 24 (suppl.): 241-282.

Tversky, A., Shafir, E. (eds.) (2004). Preference, Belief, and Similarity. Selected Writings. Cambridge, MA: MIT Press. 